\title{
Lessons from a virtual field trip: Adapting explorative and immersive learning pedagogy
}

Joseph Davies

Duke Kunshan University, China

\section{Laura Davies}

Duke Kunshan University, China

Keywords: virtual field trip; immersive learning; higher education; sino-foreign university; Covid-19.

\section{The challenge}

The COVID-19 pandemic has affected over 1,598,099,000 learners due to educational institution closures across 194 countries and all education sectors (UNESCO, 2020). One year on, the situation has improved, but for many international students and faculty, global travel restrictions make return to campus impossible. As China-based faculty at a Sino-foreign joint venture university, this is a challenge we and our international students have faced over the last eighteen months. Over this extended time period, we have been able to successfully adapt our English for Academic Purposes pedagogy to online delivery with the support of colleagues, the university's Center for Teaching and Learning, and through consultation with the relevant literature (for more details see Davies, J. et al., 2020; Davies, L. et al., 2020). However, this specific challenging case refers to how we adapted a new explorative mini-term course, Advertising Across Cultures, to online teaching.

As a research-intensive liberal arts Sino-foreign university, Duke Kunshan University provides a multidisciplinary undergraduate curriculum that requires students to explore disciplines beyond their major. For example, all students enroll in an intensive, fun, one-week exploratory mini-term course, enabling students to explore new areas of interest in a high-impact, low-risk format. Unfortunately, the inaugural 2020 mini-term was postponed until spring 2021 in anticipation for international faculty and students to return to campus. However, as many were still unable to return, a rapid and unexpected shift to online delivery was required. 
Moreover, the fact that the course was designed as an immersive in-person course about advertising built around an explorative advertising field trip to Shanghai further complicated the process. Additional challenges centred around how to deliver the course online to both Chinese students studying on campus and international students spread across global time zones studying online.

\section{The response}

After researching several alternatives, Google Maps Street View was chosen to host an immersive virtual field trip. Students first worked through customised user guidelines (see Appendix A), completing treasure hunts of global locations by searching for specific advertisements teachers had pre-selected for their application of course-related advertising principles. Then students (virtually) travelled the globe independently to find a minimum of three advertisements in different countries that demonstrated course-related theories and, if appropriate, students could also physically explore their current locations. In order to promote risk-free exploration of unfamiliar course content and to reduce test anxiety (Cassady \& Johnson, 2002), all mini-term courses are ungraded but require students to actively engage to pass. To evidence such engagement, and build a class corpus of authentic global advertisements, students posted their advertisements in-situ on a class Padlet map where they engaged in asynchronous online discussion before participating in synchronous followup classroom discussion (see Appendix B).

Anonymous course evaluation feedback showed that students valued the virtual field trip experience with several citing this as the highlight of the course:

I enjoyed the virtual field trip, for I could visit different places in the world with a simple click. I learnt various advertisements in different parts of the world. Since I had not participated in a virtual field trip, or used Google Maps to see the street view, it was a meaningful experience for me. 
I think the virtual field trip was designed in the best way to replace the physical trip and I think being able to apply the concepts learned and observe the adverts from a more knowledgeable perspective was very nice.

My favourite part of the mini-term course is the virtual field trip because it is a new way for me to explore and expand my perspective.

I liked the ability to look at the area through different times and see how adverts evolved.

\section{Recommendations}

From our experience of utilising Google Maps Street View to conduct a virtual field trip, we found several benefits for exploratory learning that could be easily adapted for various inperson and online teaching contexts. Firstly, this task promotes learner agency, which is crucial for computer-supported collaborative learning (Wise \& Schwarz, 2017), as students explore independently to apply course-related intercultural communication and advertising theories. Furthermore, the interface allows students to view different time periods to explore how trends in a particular area have evolved, which is relevant for many fields and is not possible during a physical field trip. This aligns with Siemens' (2005) Connectivism theory of learning which explains how learners use the vast information available on the internet to make information connections beyond what can be taught in the classroom (Dunaway, 2011). Additionally, as Google Maps is a free tool, the time and financial resources saved in comparison to organising a physical field trip could provide opportunities for learners who otherwise would not be able to participate. Finally, the vast range of global areas explored and subsequent examples shared amongst learners far exceeds what could be achieved by physically visiting one location, which complements courses like this that have an intercultural focus.

To conclude, we strongly recommend using Google Maps Street View for a variety of face-toface and online learning contexts and levels. It is free, safe, can be used to transport students 
to a variety of different global locations and time periods, and can develop learner agency. However, to maximise online learning, it is important that tasks are well designed and link directly to course learning outcomes (see Thomas and Reinders, 2010 for some excellent Computer Assisted Language Learning-related insights). Secondly, it is important to first train students how to confidently use the interface with detailed user guidelines and example screencast videos. It is our opinion that such scaffolding is best done in person or at least synchronously where teachers are on hand to demonstrate the interface and troubleshoot with students. Furthermore, virtual scavenger hunts can be easily designed using Google Maps Street View and are an engaging way to encourage independent exploration of various topics. Finally, to encourage course engagement, we recommend creating a class Padlet map for students to post field trip findings and interact via follow-up written, spoken or video responses. Ultimately, we have been impressed with the ease, versatility and explorative impact of Google Maps Street View and will be adding this to our teaching repertoire for various future in-person and online teaching contexts.

\section{References}

Cassady, J. C., and Johnson, R. E. (2002) 'Cognitive Test Anxiety and Academic Performance', Contemporary Educational Psychology 27(2), pp. 270-295. https://doi.org/10.1006/ceps.2001.1094

Davies, J. A., Davies, L. J., Conlon, B. M., Emmerson, J., Hainsworth, H., and McDonough, H. G. (2020) 'Responding to COVID-19 in EAP Contexts: A Comparison of Courses at Four Sino-Foreign Universities', International Journal of TESOL Studies 2(2), pp. 3251. Available at:

https://www.tesolunion.org/journal/details/info/2MzcueZGQ3/Responding-to-COVID19-in-EAP-Contexts:-A-Comparison-of-Courses-at-Four-Sino-Foreign-Universities (Accessed: 27 May 2021) 
Davies, L. J., Chiocca, E. S., Hiller, K. E., Campbell, M., and Naghib, S. (2020) 'Transformative Learning in Times of Global Crisis: Reflections on Collaborative Working Practice', CEA Critic 82(3), pp. 218-226. https://doi.org/10.1353/cea.2020.0036.

Dunaway, M. K. (2011) 'Connectivism: Learning theory and pedagogical practice for networked information landscapes', Reference Services Review 39(4), pp. 675-685. https://doi.org/10.1108/00907321111186686

Siemens, G. (2005) Connectivism: A learning theory for the digital age. International Journal of Instructional Technology and Distance Learning 2(1). Available at: http://itdl.org/Journal/Jan 05/article01.htm (Accessed: 25 May 2021).

Thomas, M., and Reinders, H. (2010) Task-based language learning and teaching with technology. Bloomsbury.

UNESCO. (2020) COVID-19 Educational Disruption and Response. Available at: https://en.unesco.org/covid19/educationresponse (Accessed: 5 April 2020).

Wise, A., and Schwarz, B. (2017) 'Visions of CSCL: Eight provocations for the future of the field', International Journal of Computer-Supported Collaborative Learning 12, pp. 423 467. https://doi.org/10.1007/s11412-017-9267-5

\section{Author details}

Joseph A. Davies is lecturer of English language at Duke Kunshan University. He holds an MA in TESOL with Applied Linguistics, a DELTA and Senior Fellowship of the Higher Education Academy (SFHEA). His current research focuses on feedback literacy and EAP pedagogy within sino-foreign higher education contexts.

Laura J. Davies is the Assistant Director of EAP, and lecturer of English language at Duke Kunshan University. She holds an MA in TESOL with Applied Linguistics and a DELTA, 
specializing in higher education English language teaching management. She is also a Senior Fellow of the Higher Education Academy (SFHEA). Her current research focuses on intercultural engagement, student identity, and course design. 


\section{Appendix A: Google Maps Virtual Field Trip User Guide and Task Instructions}

\section{Mini-term Advertising Across Cultures - Virtual Tour Scavenger Hunt Task Brief}

Today we will take a global tour of outdoor advertising and see if we can apply some of the theories, ideas and concepts from our mini-term course to the world of global outdoor advertising. In order to take part you will need a stable internet connection and access to the university VPN. This virtual tour activity should take you approximately 2 hours.

The purpose of the virtual tour is to give you the freedom to explore different locations across the globe and to identify different patterns and styles of outdoor advertising. As you explore different countries, cities, and towns you should be actively on the lookout for interesting examples of outdoor advertising and in particular any examples that use the theories and appeals we have discussed in class.

\section{You goals for this virtual tour activity are as follows:}

- Explore a minimum of 4 countries $\circ$ If you are in a suitable location, you may physically explore your current location for one of the example countries. Alternatively, this task can be completed completely online

- Find an interesting example of outdoor advertising from 3 different countries

- Find examples that clearly demonstrate the theories and appeals covered on this course

- Consider how intercultural communication theory could be used to explain each advertising strategy based on the context (i.e. the country and specific location where the ad was found)

- Take clear screenshots of your ads in context to share with the class

- Post an image (your screen shot in context) for each of your 3 final ads with a brief description/analysis on the class Padlet map

- Take notes explaining your 3 ads, the appeal they use and any Intercultural theory, and be prepared to discuss this in our upcoming synchronous session that follows

*Please note, as these are static, print advertisements, often intended for a wide general audience with various demographic characteristics (it is harder to segment the market for outdoor ads), it may be more challenging to clearly identify advertising appeals than in a longer video advertisement - this is your challenge to explore and search carefully for suitable examples.

\section{How to Access the Virtual Tour}

The computer software we will use for the virtual tour is Google Maps, using street view.

- Go to Google Maps on your web browser

- Google Maps

- Search for a city of interest to explore 


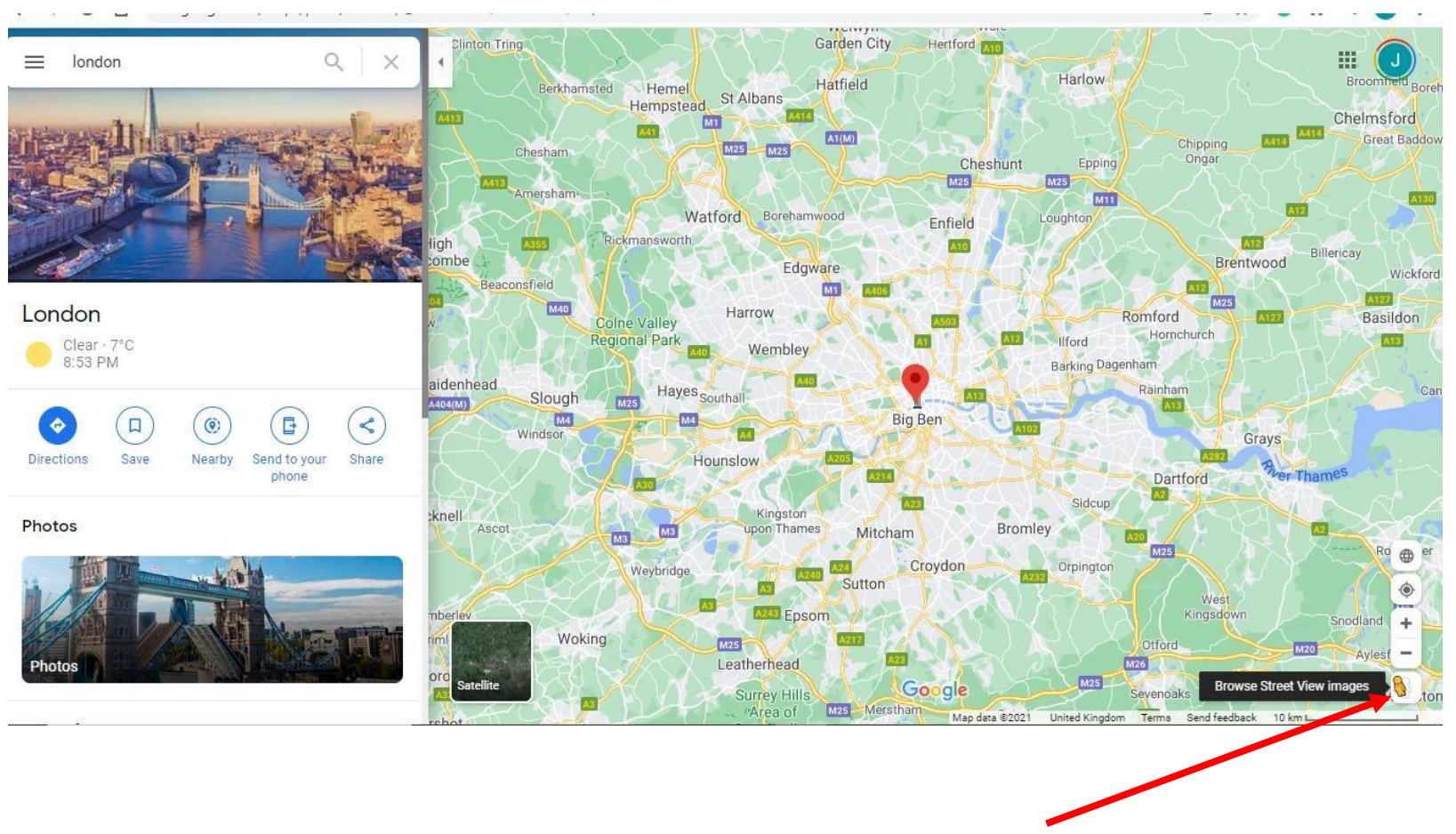

- Click on the street image button at the bottom to explore at street level for interesting advertisements

- As you can see below, countries with blue highlights can be explored in detail using street mode. For example, you can explore most European, North, Central, and South American countries as well as South Africa, Kenya, Japan, South Korea, Australia, Sri Lanka, Thailand, Malaysia, Singapore, The Philippines, Mongolia, some limited streets in China and more!

- You can often zoom in to get clear images of the sights around you and then capture the image using a screen shot.

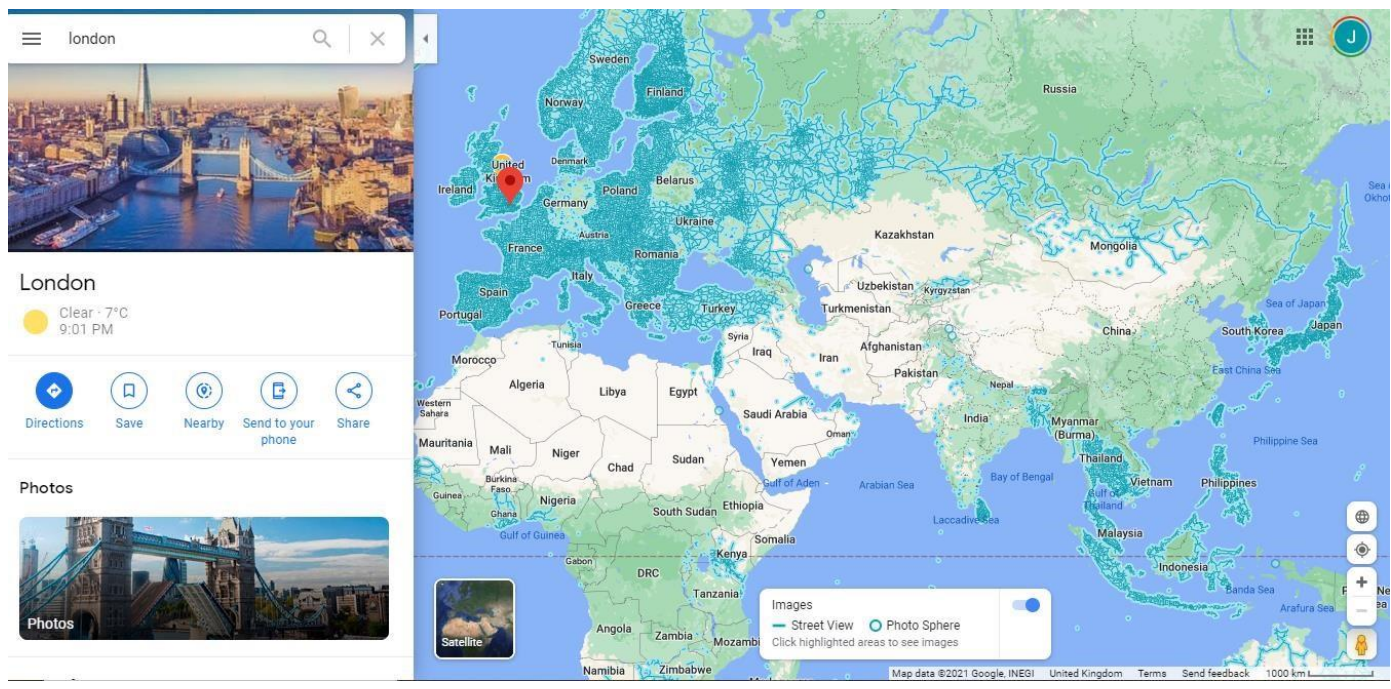

- Simply search for a place of interest or zoom in and click on a blue street to enter the virtual tour. 


\section{The Google Maps street view interface}

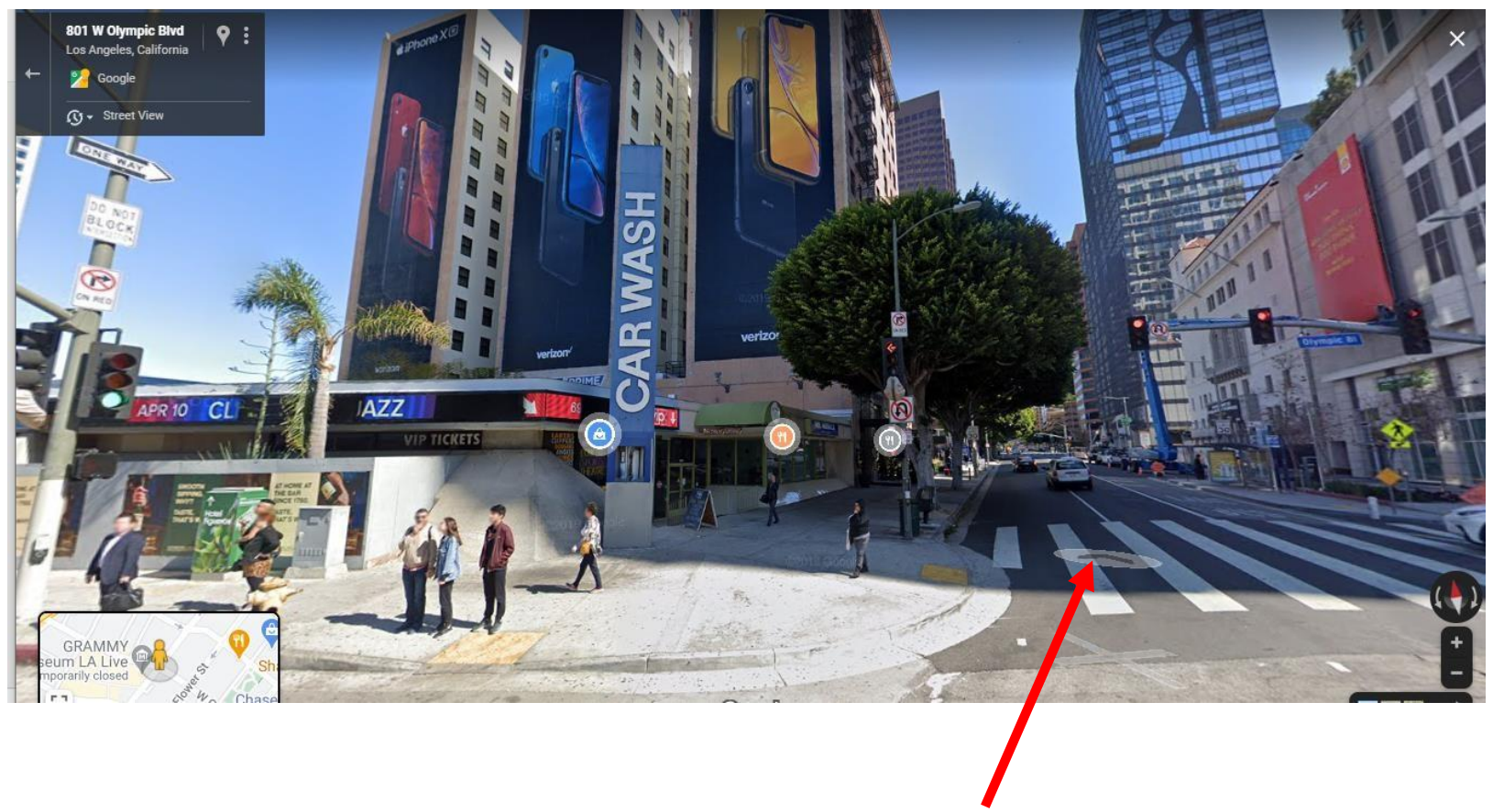

- You can move your mouse to look around (up down, left \& right) and click the arrows to move along a street (see below as I walk along a street in LA)

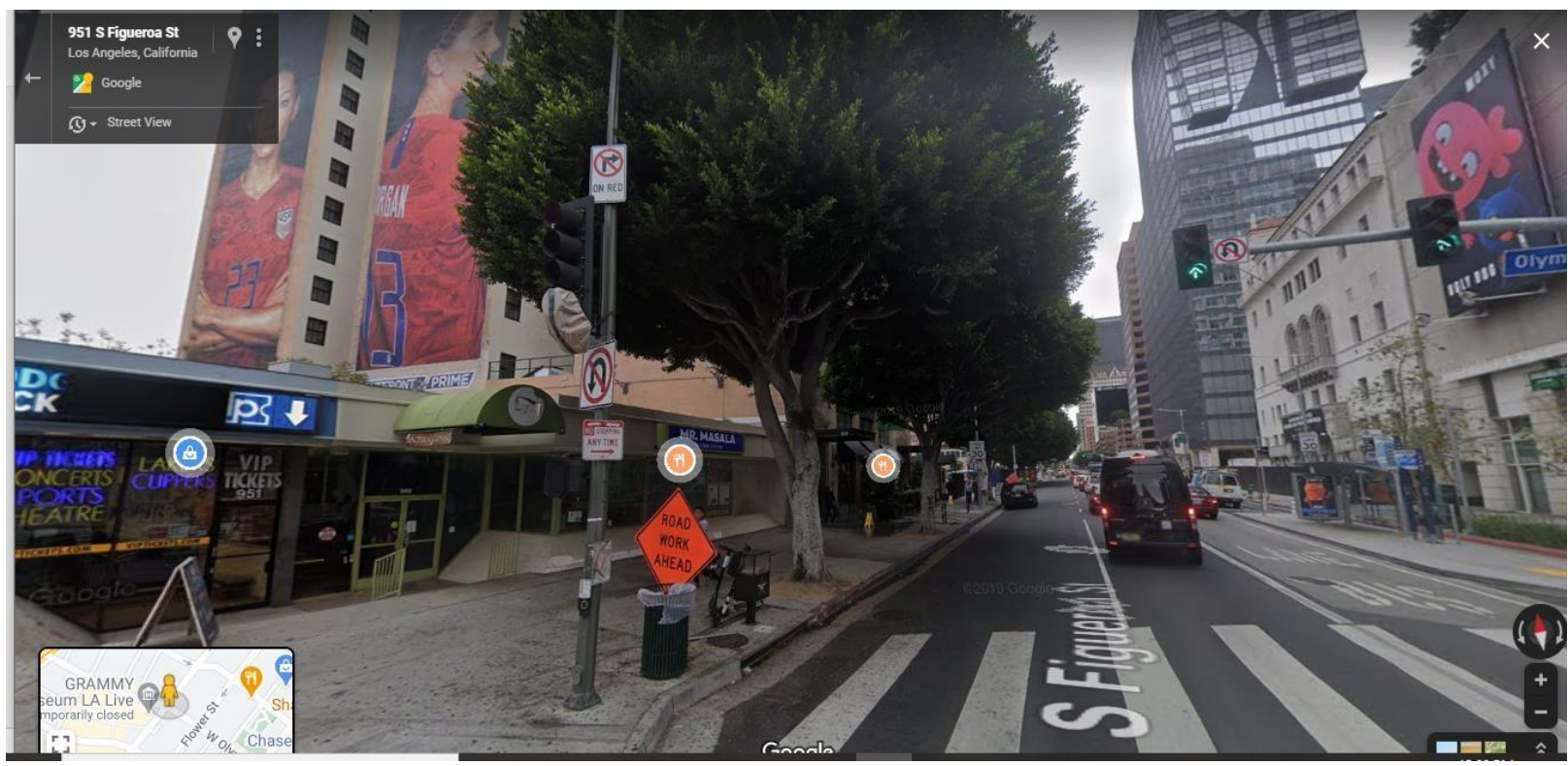




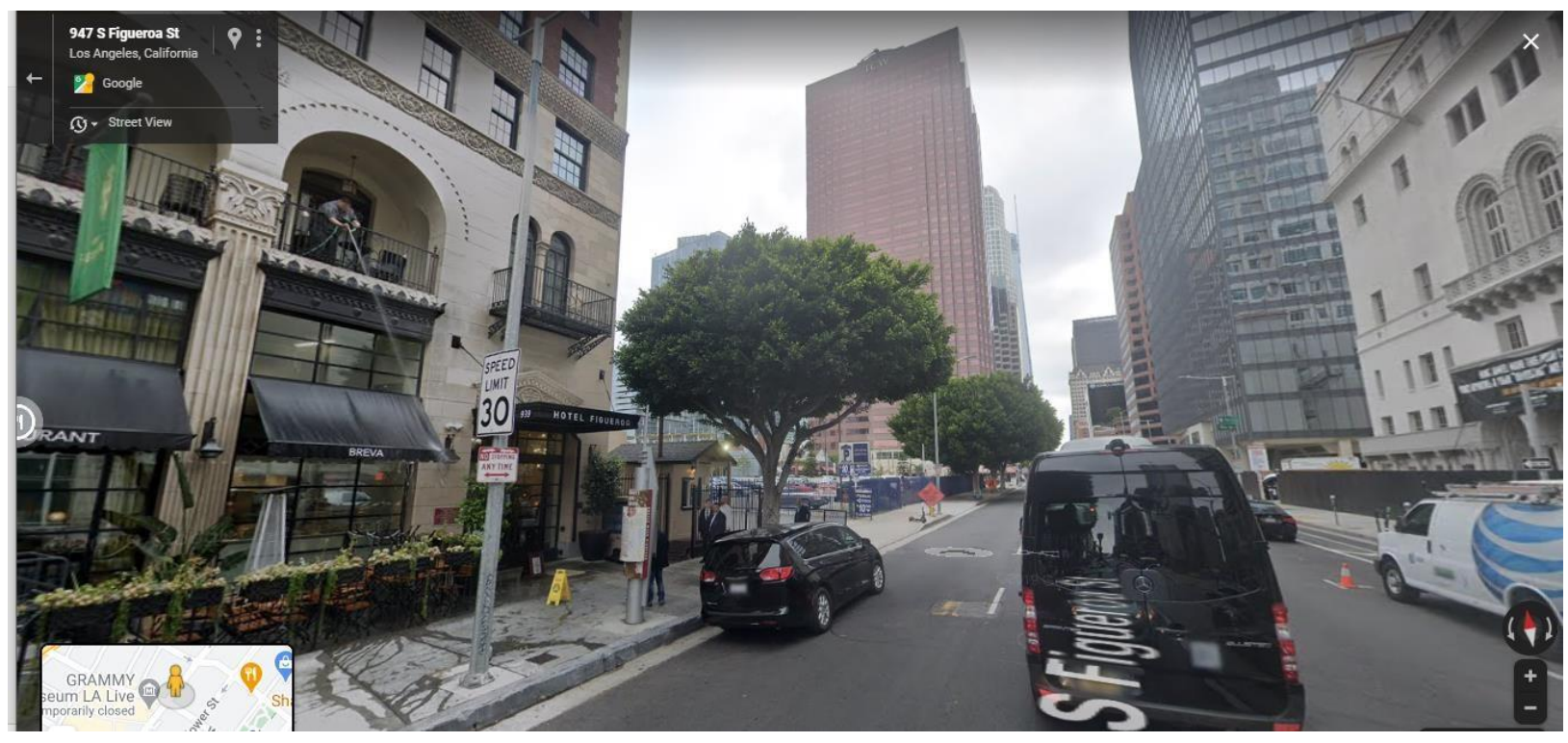

- To move to another country/city/town, simply click the back arrow in the top left and search for a new location and start again.

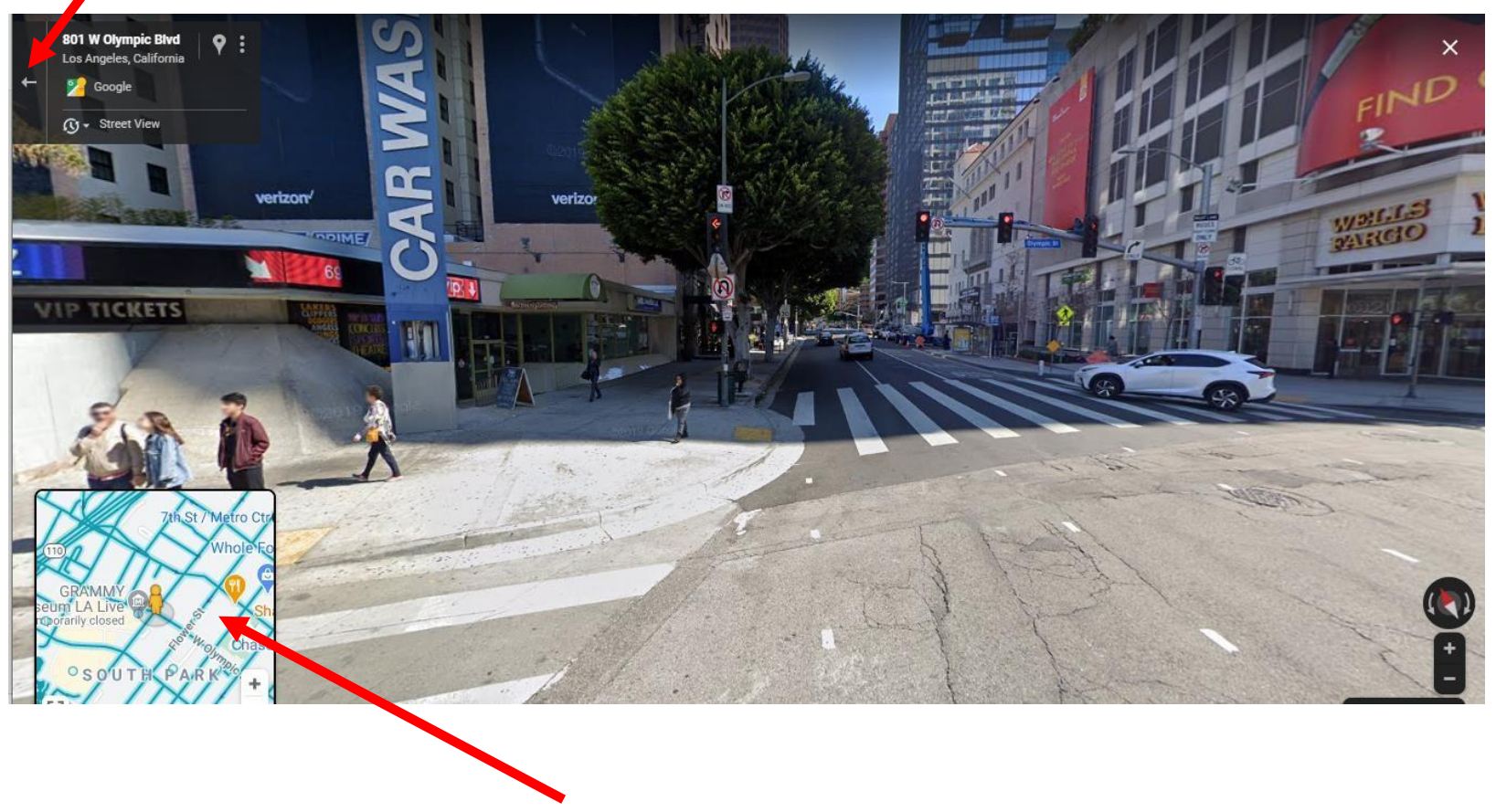

- To move somewhere else in the local area, hover your mouse over the map in the bottom left corner and click on a blue street. You will be taken to that street. 
- Another key feature of Google Maps street view is that you can look at how a location has changed over time and view different images from different years. To do this click the small clock in the top left corner next to street view

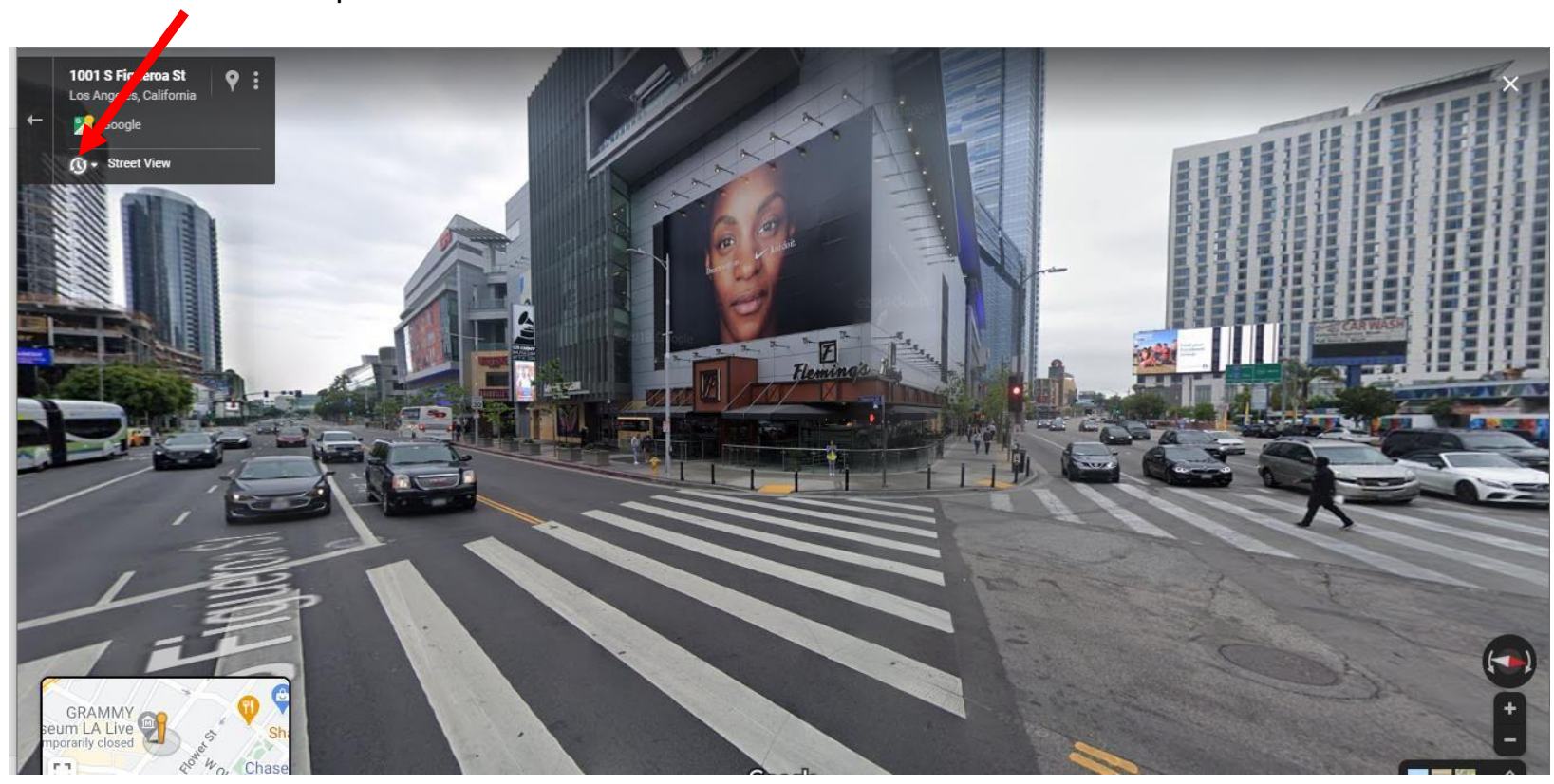

This lets you click different periods in time and view how the area has changed (see below for a glimpse of a key LA junction from 2008 - 2019). The interesting thing for us is that we can see how key outdoor advertising has changed and with it the social message and different use of advertising appeals. This also gives you many more examples of outdoor ads to complete your virtual tour scavenger hunt challenge.

\section{LA, 2008}

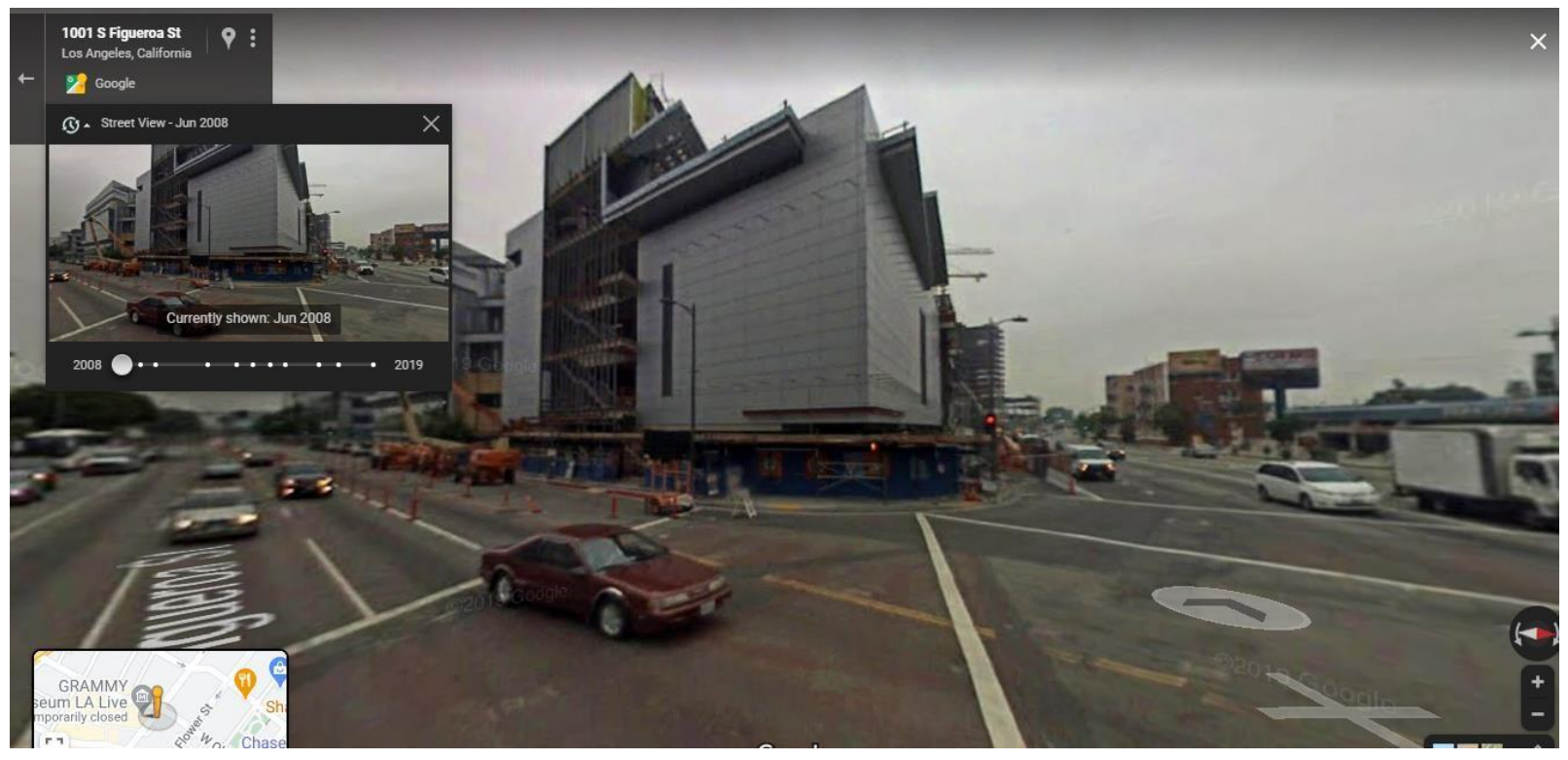


LA, 2014

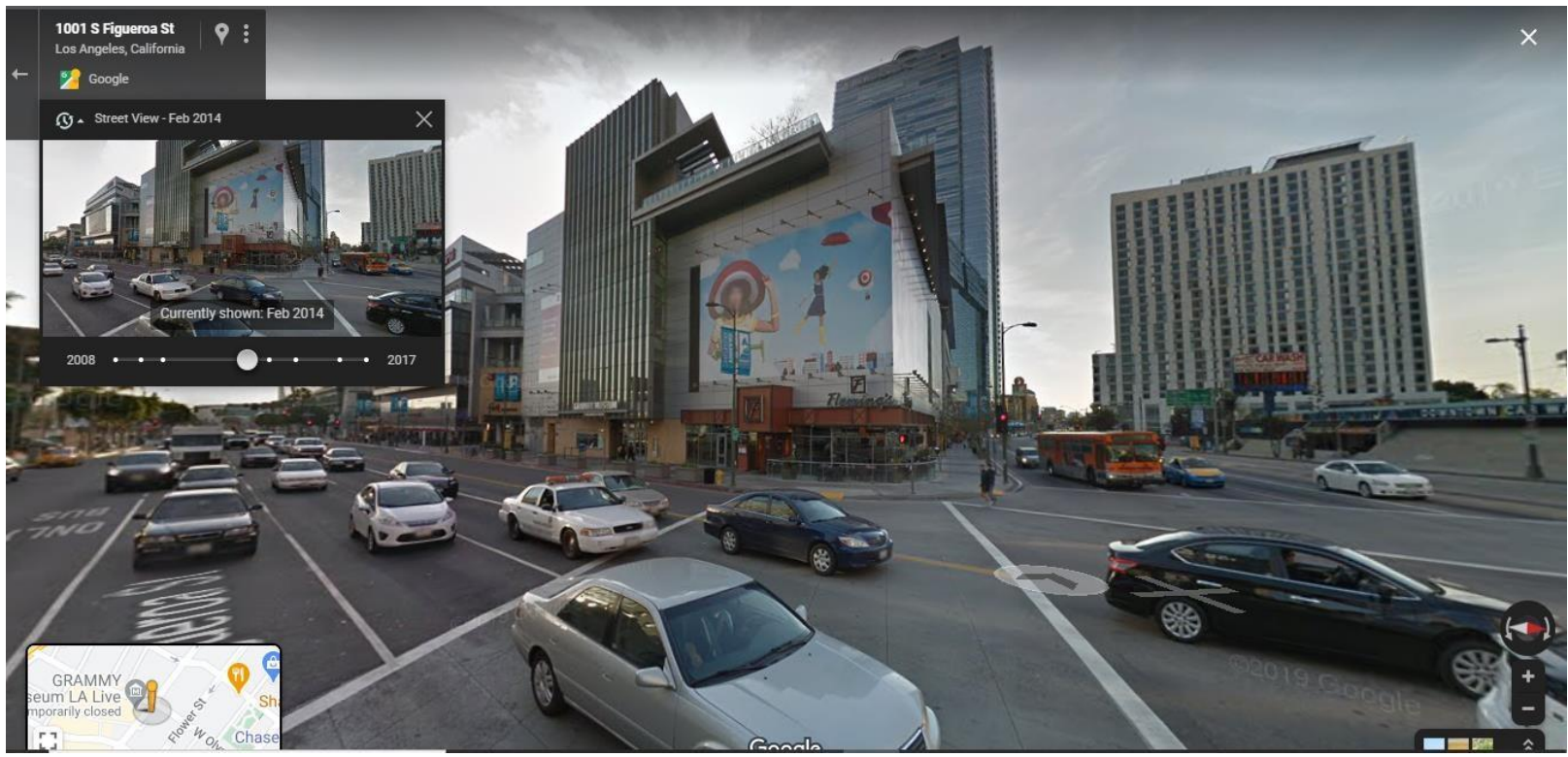

LA, 2019

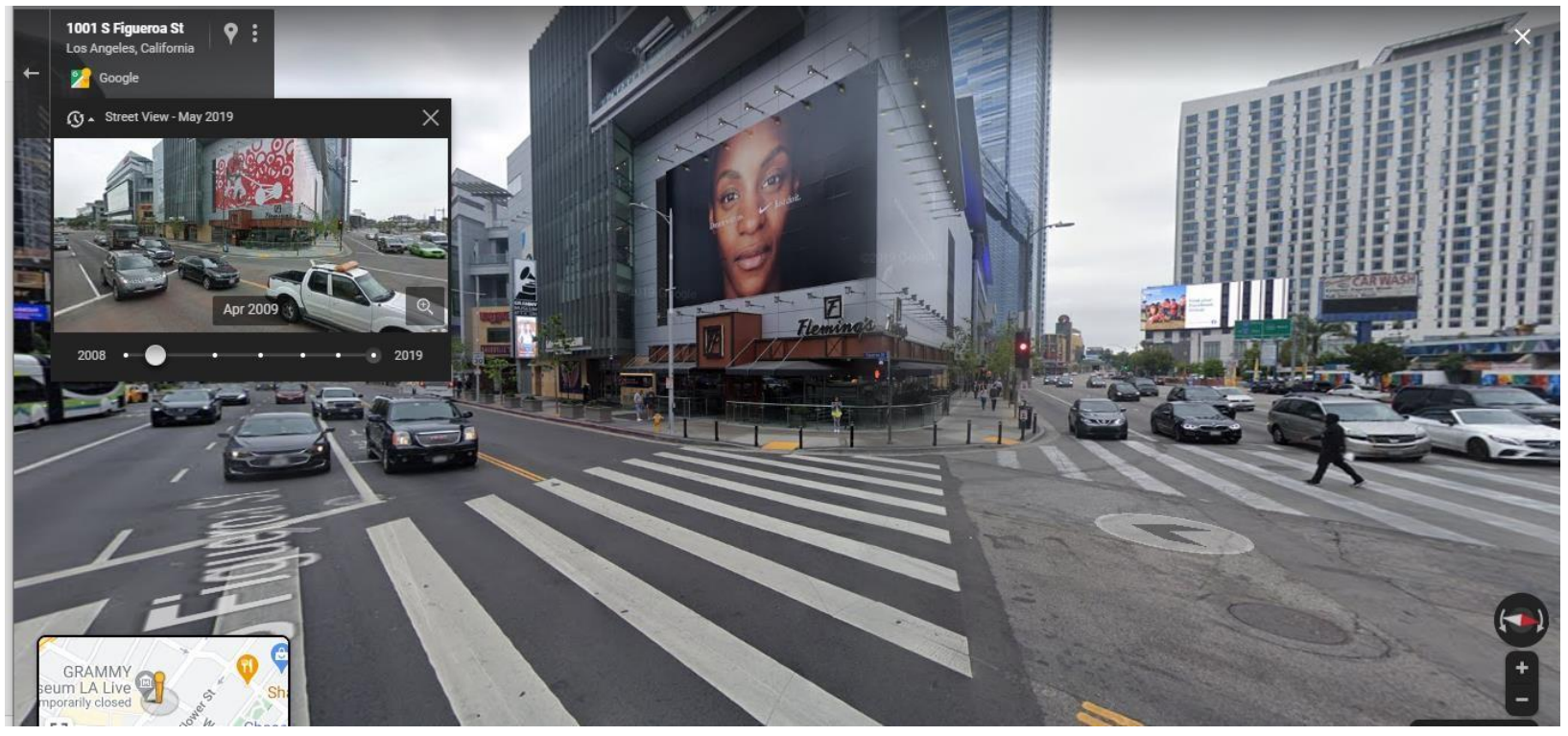

Tip: Don't forget to zoom in and look at bus advertisements and ads on bus stops on the sidewalk as they can also provide some interesting examples

\section{Further Examples and Good Places to Look for Outdoor Advertisements}

This BBC article is a good starting place to find key global hotspots for outdoor advertising. Considering this article was written in 2014, imagine how much this advertising space would be worth today. Have you been to any of these places? 
Below are some specific places around the world to help you find interesting advertisements. Just click on the location text to be taken directly to the location in Google Maps. Remember to look at these locations over past years also to increase your exposure to different examples. You should also try and look at other locations that you are interested in.

\section{Nathan Road, Tsim Sha Tsui, Kowloon, Hong Kong}

Explore the local area and see if you can find the large advertisement at 26 Nathan Road that states 'luxury beyond imagination'

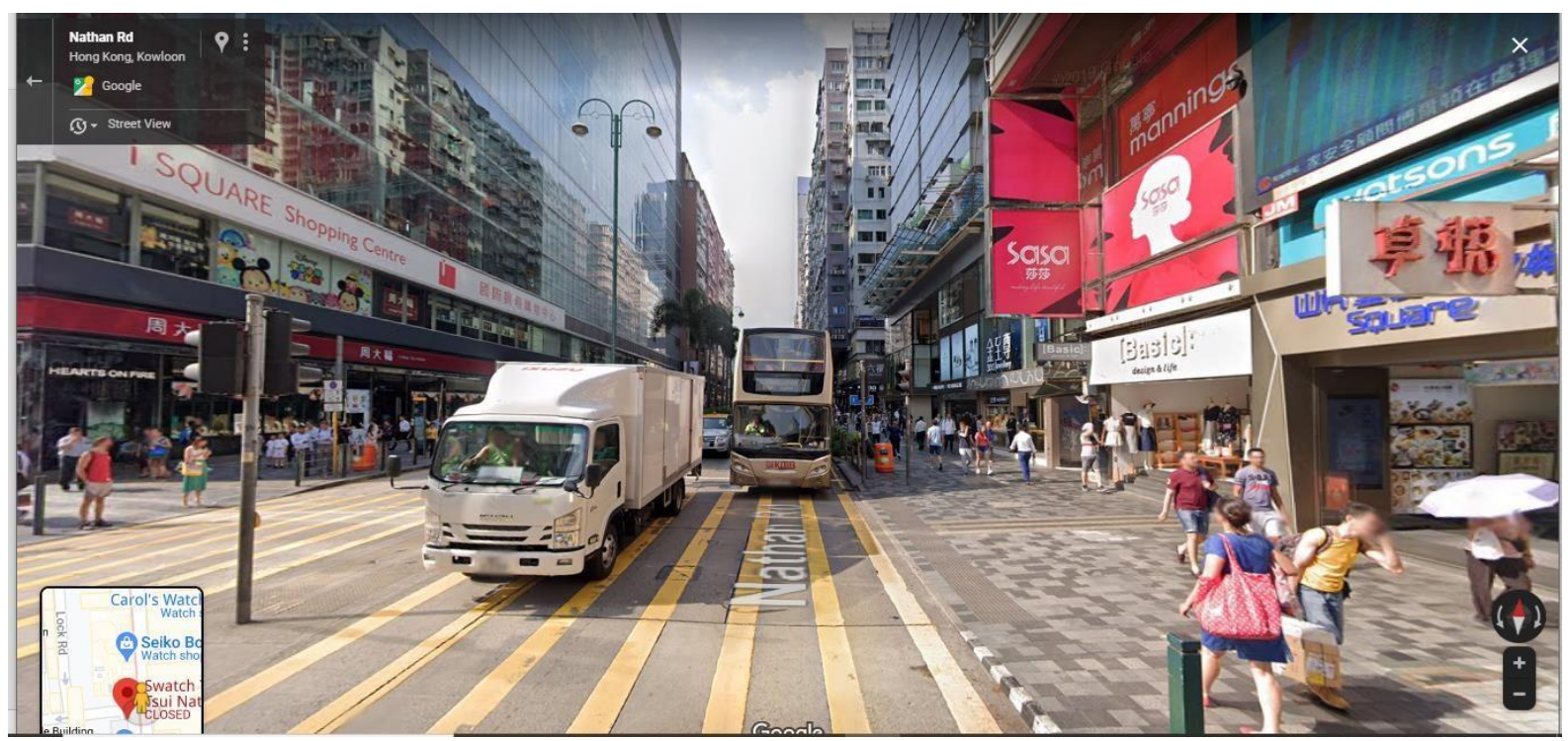

\section{Times Square, New York, USA}

Explore the local area and see if you can find the large advertisement with the slogan "love comes in every shade". What kind of product do you think this will be advertising?

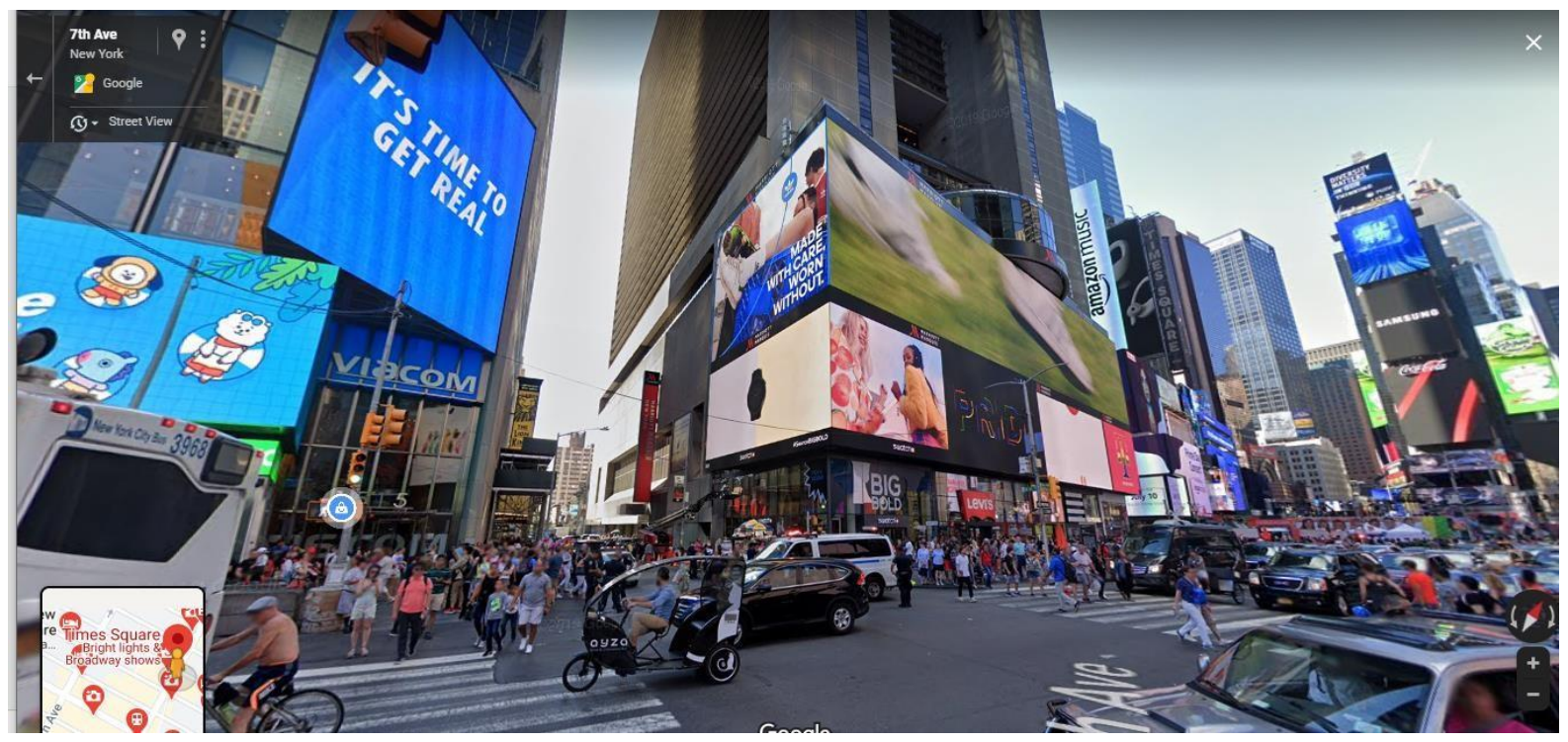




\section{Piccadilly Circus, London, UK}

Explore the local area. What do you notice about the Coca-Cola advert? What does the Hyundai advert quotation mean? How is this relevant to the location and context of this advertisement?

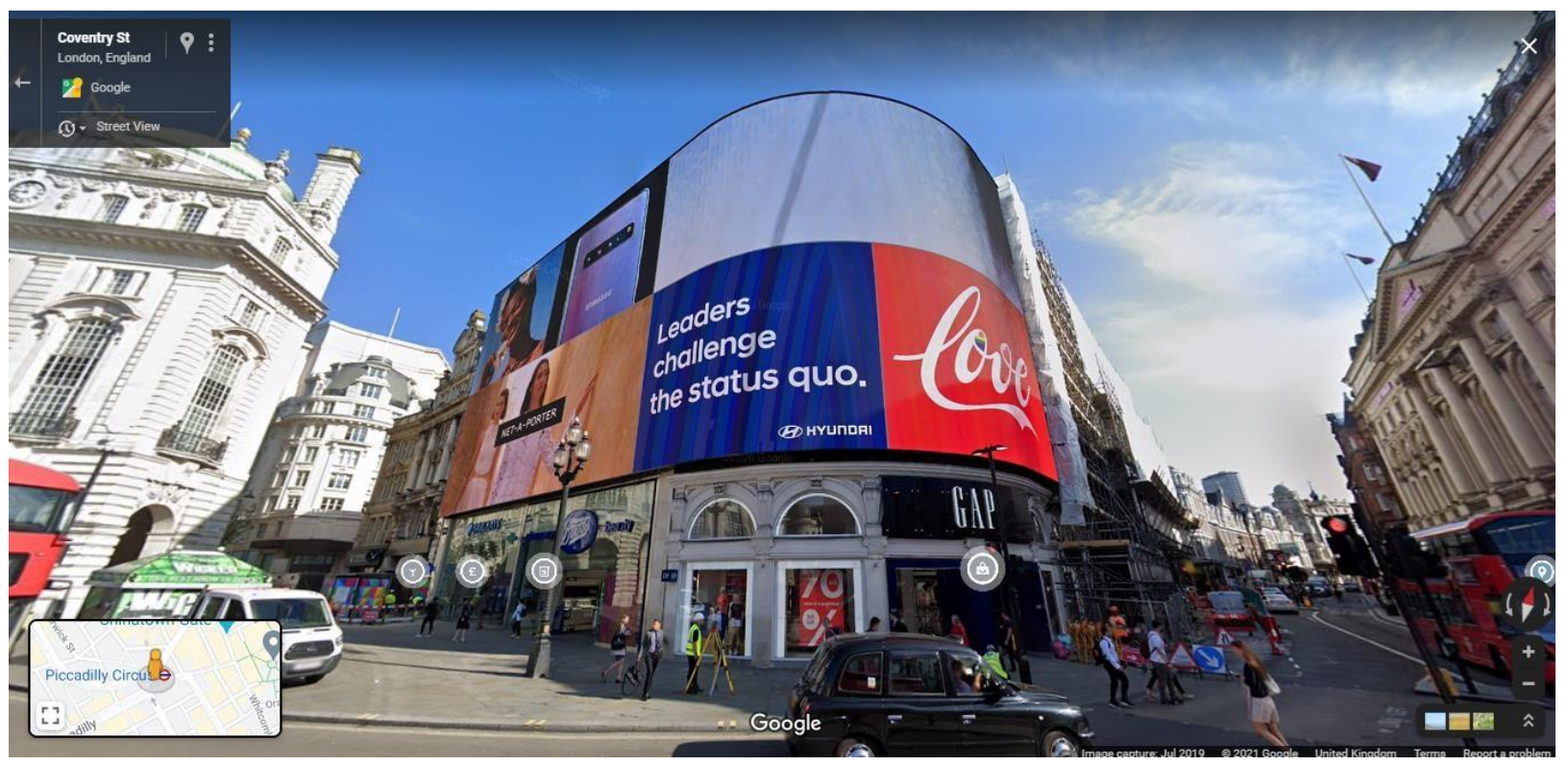

\section{West Olympic Boulevard, LA, USA}

Explore the local area. Try to spot the Nike advert with the tag line "Be the hero you didn't have". How does this relate to the sport and cultural identity of the individual portrayed?

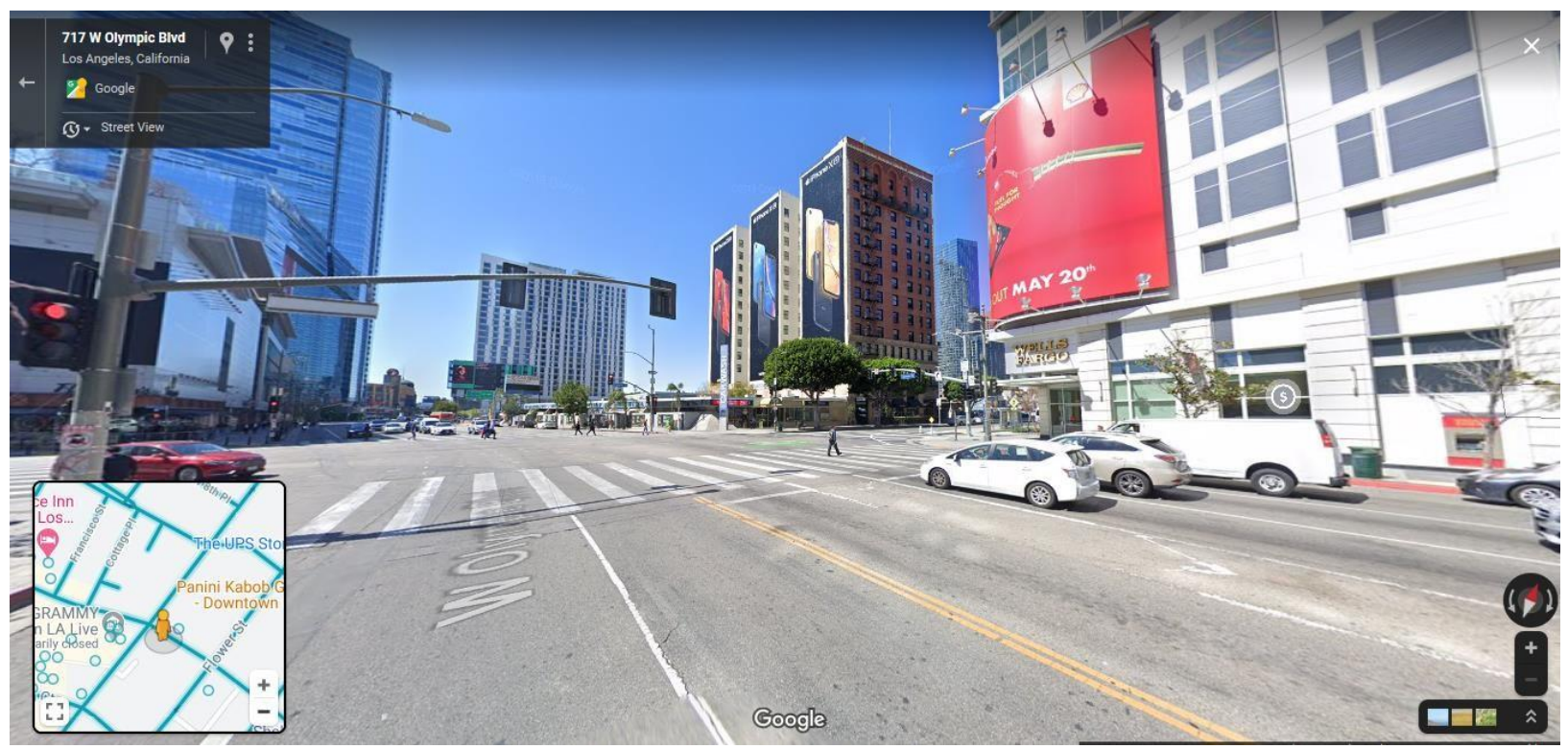

\section{East Nanjing Road, Shanghai, China}

\section{Shubuya, Tokyo, Japan}




\section{Outfront media finder}

This is an excellent website that locates thousands of outdoor advertisement examples in America and Canada. You can search for different media types but specifically searching for 'walls' will actually show the advertisements. Other media searches only show the locations. You should use this resource to identify key areas with high volumes of outdoor advertisements. You can then find this location on Google Maps street view and explore the area further to see the actual examples.
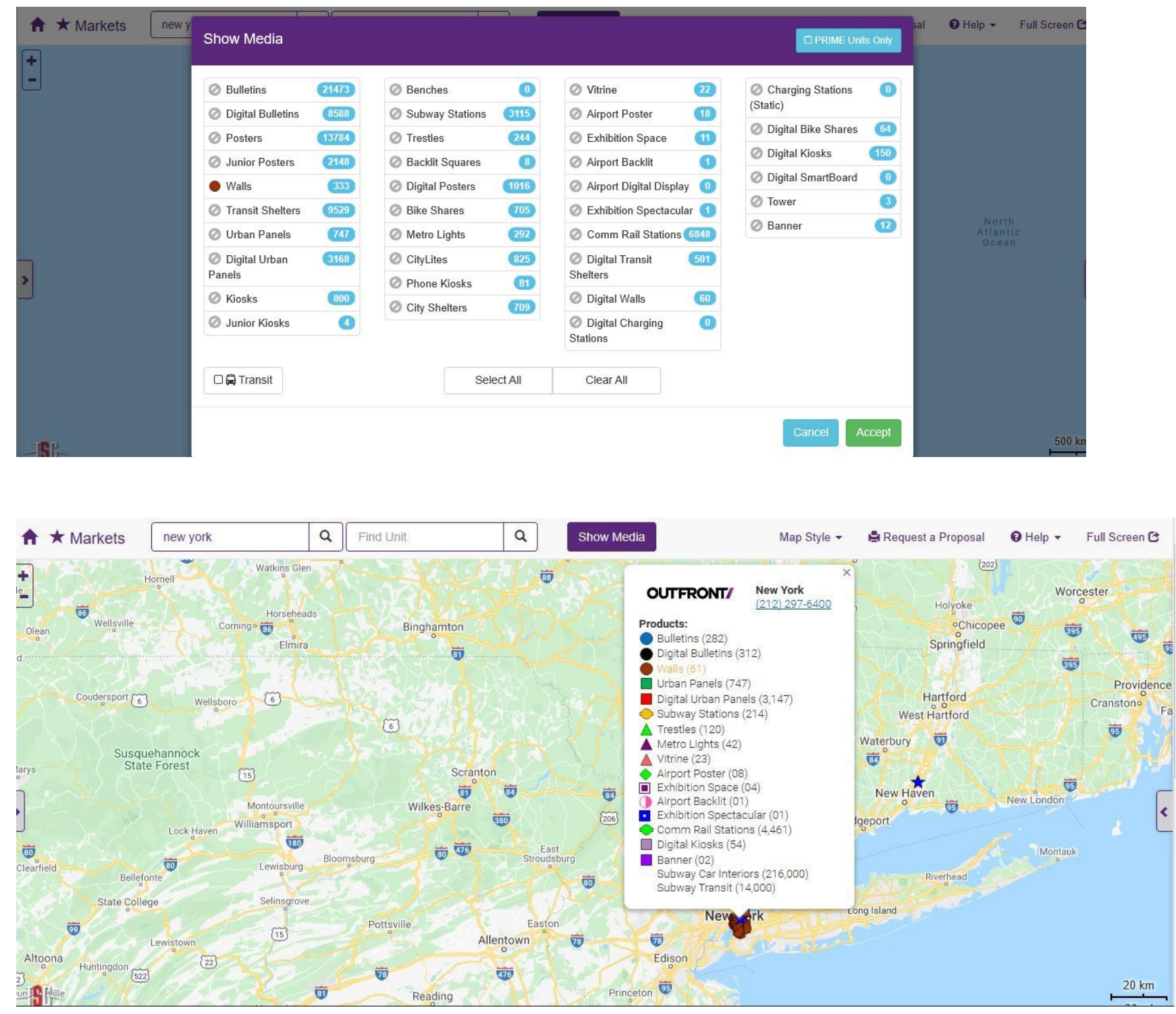

Zoom in and click on the brown 'wall' buttons to see the image of the advertisement 


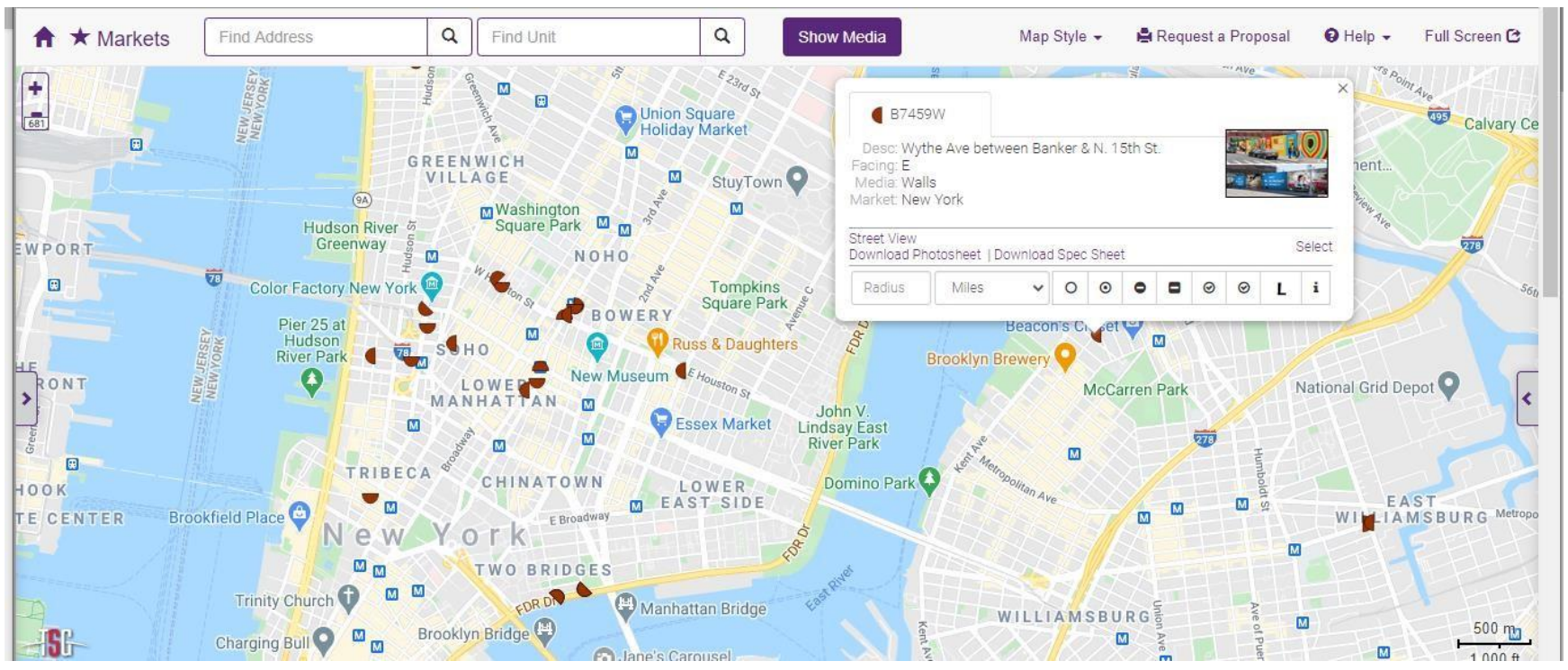

Click the image to see a larger image with more details

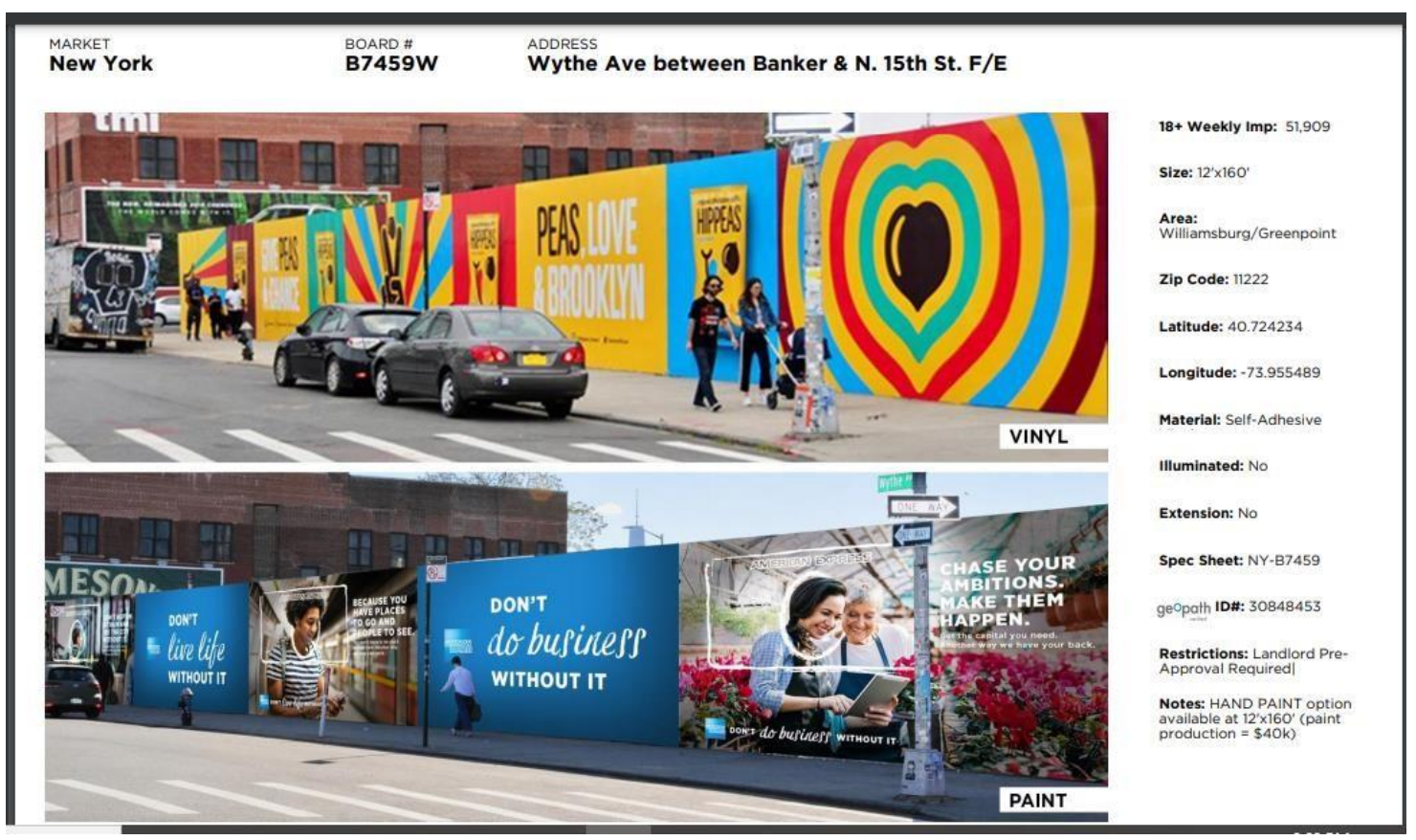

\section{Global}

This advertising agency is one of the leading producers of outdoor advertising in the UK. You can find details of the kinds of outdoor advertising they create and key demographic characteristics of the ads' viewers below.

To help with your virtual tour treasure hunt, Global lists key roads/streets in major UK cities where their outdoor advertising billboards are located. You can find these locations here. Just select a city of interest and then go to these locations on Google Maps street view and explore for specific examples. 
- Click on a city of interest to see the key locations

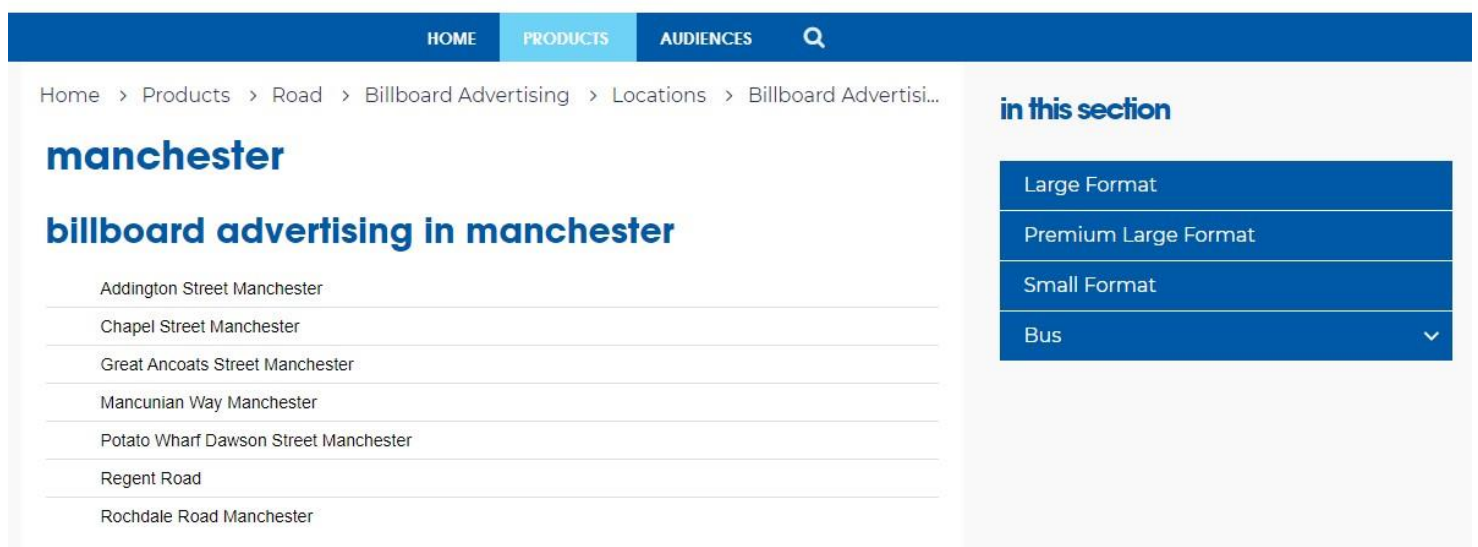

- Then click the location to find specific details of where the billboard is location to help your search on Google Maps street view

\begin{tabular}{|c|c|}
\hline AUDIENCES & \\
\hline Home > Products > Road > Billboard Advertising > Locations > Billboard Advertisi... & in this section \\
\hline chapel street manchester & Large Format \\
\hline $\begin{array}{l}\text { A solus digital site located right in the heart of Manchester benefiting from high dwell time } \\
\text { and long visibility from two directions of traffic heading into the city }\end{array}$ & Premium Large Format \\
\hline $\begin{array}{l}\text { Just yards away from the main shopping areas of Market Street and the bars and } \\
\text { restaurants on Deansgate }\end{array}$ & Small Format \\
\hline An absolute must for targeting consumers and event goers & Bus \\
\hline
\end{tabular}




\section{Appendix B: Virtual Field Trip Design and Implementation Process}

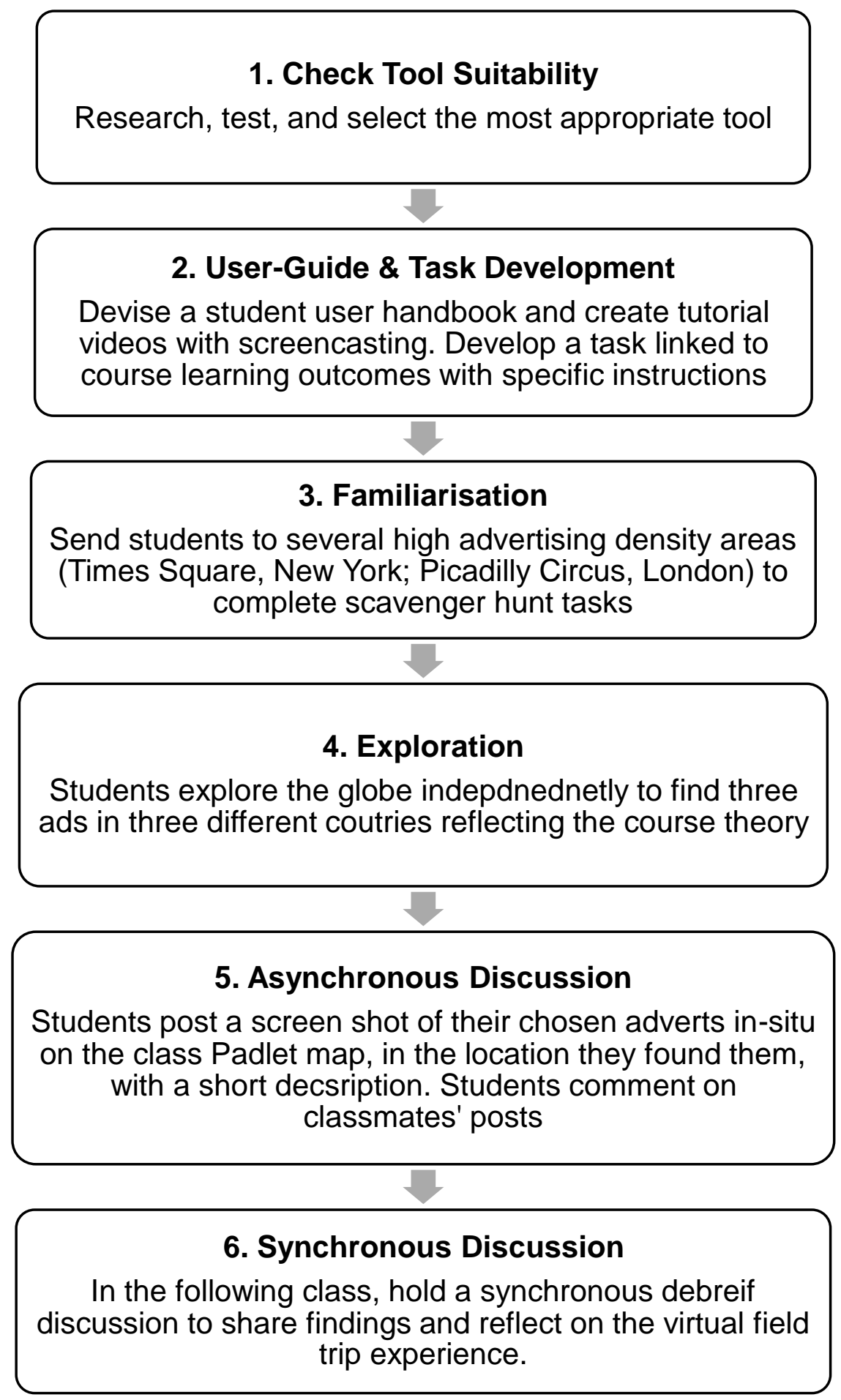

